\title{
Remisión espontánea libre de tratamiento en leucemia mieloide crónica, un nuevo concepto
}

\author{
Humberto Martínez, Jaime Valdés
}

Correo electrónico: humbertomartinez48@hotmail.com

Introducción: la leucemia mieloide crónica (LMC) representa, con el advenimiento de los inhibidores de tirosina quinasa, un modelo de enfermedad en el cual las terapias dirigidas pueden controlar el cáncer a largo plazo. Existe una creciente literatura sobre la descontinuación segura del tratamiento en los pacientes que logren una respuesta molecular profunda. En general, se considera que los pacientes no deben interrumpir la terapia a menos que se encuentren en un ensayo clínico o sean parte de un programa estructurado de excelencia en el manejo de LMC, y que cumplan unos criterios estrictos para ser considerados candidatos.

Métodos: exponemos el caso de un paciente con diagnóstico de LMC de 10 años de evolución, quien interrumpe la terapia de manera voluntaria, manteniendo la respuesta molecular mayor luego de 12 meses sin tratamiento.

Resultados: hombre de 55 años de edad con diagnóstico de LMC Filadelfia positivo desde el año 2008 tratado con agentes citorreductores, y antecedente de hipertensión arterial. Inicia tratamiento con imatinib desde el año 2009 de forma muy irregular luego de desarrollar una fase acelerada. En el año 2010 tuvo interrupción del tratamiento relacionada con adherencia por cerca de dos meses. En febrero de 2011 continuó tratamiento de forma regular hasta junio de 2017, donde se documenta una PCR para BCR-ABL no detectada con un límite del 0,00055\%. El paciente decide suspender el tratamiento de forma voluntaria, y tiene pérdida en el seguimiento hasta febrero de 2018, cuando nuevamente es valorado de forma ambulatoria con un hemograma y una química sanguínea normales, junto a una PCR para BCR-ABL mediante técnica estandarizada a $-4,5$ a 5,0 logaritmos, evidenciando un nivel de transcrito detectado en el $0,0096 \%$, manteniendo la respuesta molecular mayor. El tiempo total de exposición a imatinib fue de ocho años.

Conclusión: este caso es el primero en nuestro conocimiento reportado sobre la remisión libre de tratamiento espontánea. La RLT puede ser posible entre nuestros pacientes, pues en la actualidad no existen ensayos clínicos en nuestra población que tengan como objetivo demostrar la viabilidad de la descontinuación en la población latinoamericana.

\section{Medición de tiempo de trombina diluido en los pacientes anticoagulados con dabigatrán de consulta externa del Hospital Militar Central. Noviembre de 2016}

\author{
- Gloria Ramos, Óscar Reyes, María Alejandra Bravo, Barbarita Mantilla
}

Correo electrónico: gloriaramoshmc@gmail.com

Introducción: el dabigatrán es un anticoagulante directo que actúa inhibiendo la trombina vinculada al coágulo. Aunque no es necesario hacer monitoreo estricto de las concentraciones de este, debido a su predictibilidad farmacocinética y farmacodinámica, existen métodos cualitativos y cuantitativos para realizarlo; entre los métodos cuantitativos, se encuentran las concentraciones plasmáticas de fármacos medidas con el tiempo de coagulación de ecarina y el tiempo de trombina diluido. El objetivo de este trabajo fue medir el tiempo parcial de trombina en los pacientes anticoagulados con dabigatrán por fibrilación auricular del Hospital Militar Central.

Métodos: previo consentimiento informado, se tomaron muestras de 90 pacientes que asistían a consulta externa con fibrilación auricular que se encontraban recibiendo dabigatrán a dosis de $110 \mathrm{mg}$ cada 12 horas o 150 mg cada 12 horas; dentro de los requisitos era necesario haber tomado el medicamento dos horas antes de la toma de la muestra. A todas las muestras se les procesaron diferentes pruebas de coagulación, entre ellas el tiempo de trombina diluida.
Resultados: se presentó una variabilidad del $62,5 \%$ en los niveles de dabigatrán en las diferentes muestras. La mediana de concentración del medicamento fue de $124 \mathrm{ng} / \mathrm{dl}$ (p10-p90: 42,89-257) para los pacientes con dosis de $110 \mathrm{mg}$ y de 160,77 ng/dl (p10-p90: 44,26323,93 ) en los pacientes con dosis de $150 \mathrm{mg}$. Solo dos pacientes presentaron eventos hemorrágicos, en los cuales los niveles de dabigatrán se hallaban elevados en comparación con la mediana reportada en los demás pacientes.

Conclusión: existe una gran variabilidad entre los niveles de dabigatrán medidos por tiempo diluido de trombina; la dosis tomada presentó una relación proporcional a la concentración encontrada; solo hubo dos eventos adversos sin aspectos similares. No hay estudios en la población que evalúen las concentraciones de dabigatrán con esta prueba, por lo que estos resultados son un primer acercamiento sobre el comportamiento de los niveles plasmáticos de dabigatrán en los pacientes que reciben este medicamento. 